\title{
Media Use and Misperceptions
}

\author{
Does TV Viewing Improve our Knowledge \\ about Immigration?
}

\author{
Toril Aalberg \& Zan Strabac
}

\begin{abstract}
There is considerable evidence that many people generally misperceive the size of the immigrant population in their country, and that this may have essential political implications. In studies of political knowledge, the news media are typically said to be one important source of information that can help make people more knowledgeable. In the present article, we investigate whether there is a relationship between TV viewing, media system variations and knowledge about immigration. We base our analysis on highly comparable data from the 2002-2003 wave of the European Social Survey (ESS) and an American replication of the ESS. The results indicate that TV viewing in general is associated with lower levels of knowledge, while there is a positive but non-significant relationship between watching TV news and knowledge about immigration. Differences in the levels of knowledge between the countries are fairly large, with residents of Nordic countries being most knowledgeable and residents of the UK, US and France tending to be least knowledgeable. Aggregate explanations for variations in media influence (share of public service TV and "media systems") do not prove to be of much value in explaining differences in knowledge about the sizes of immigrant populations.
\end{abstract}

Keywords: immigration, political knowledge, media exposure, public TV, media systems

\section{Introduction}

Immigration has evolved into a major and controversial policy issue in the majority of Western countries. Still, there is considerable evidence that the public generally misperceives the size of immigrant and other minority populations. Sides and Citrin (2007) find that the uninformed are generally more opposed to both immigration and immigrants. Lack of knowledge may therefore have important political implications.

Typically, people learn about an issue if they have the ability, motivation and opportunity to do so (Delli Carpini \& Keeter 1996). While ability is often a question of education and motivation is related to personal interest, the opportunity to learn depends on the information environment and exposure to news media. The purpose of the present article is to investigate whether there is a relationship between TV viewing, media system variations and knowledge about immigration.

Over the past few decades, a rising tide of voices has blamed the news media for growing public ignorance of civic affairs. One of the central arguments has been that an 
increased market orientation has led to a relentless pursuit of sensational, superficial and populist reporting in an attempt to maintain high TV ratings (Fallows 1996). Schudson (1995) argues that all this "breathless flimflam" comes at the expense of detailed and informed debate about policy issues and hard news. So even if there is more "information" available now than ever before, this does not create more informed citizens.

Most empirical studies, however, have found a positive relationship between individuals' exposure to news, viewers' preference for public service television or quality newspapers and their level of political knowledge (e.g., Newton 1999, Norris 2000, Holtz-Bacha \& Norris 2001, Milner 2002, Prior 2005, de Vreese \& Boomgaarden 2005, Dalrymple \& Scheufele 2007). In other words, there seems to be significant individual level differences in political knowledge based on the type of news media people prefer or the type of media to which they are exposed. On the aggregate level, however, findings are more inconclusive. Holtz-Bacha and Norris (2001: 133), for instance, find no systematic media structure pattern that can explain the level of EU knowledge across 16 countries. Milner (2002: 102), on the other hand, discovers a strong positive relationship between the level of knowledge about the UN and the country's dependency on commercial TV (relative to newspapers).

In the present study, we investigate if and how TV viewing influences public knowledge about the issue of immigration in 18 countries. Inspired by Hallin and Mancini's book Comparing Media Systems (2004), we also ask whether levels of knowledge vary significantly across countries and whether there are systematic differences related to the countries' media systems. The empirical analyses are based on data from the 20022003 wave of the European Social Survey (ESS) and an American replication of the ESS from 2005.

Compared to earlier studies on media and political knowledge, our study makes three main contributions to the current research. First, while a vast majority of previous studies have been based on data from the US or a handful of European countries, our study includes a large number of European countries as well as data from the US. Second, the few comparative studies that do exist have primarily focused on knowledge of foreign affairs, such as questions concerning the United Nations or the European Union. Our focus is on public knowledge in relation to an issue that is highly relevant and controversial for domestic politics across all these countries - the issue of immigration. With this in focus, we introduce an indicator that studies of media and political knowledge previously have overlooked. It is important to stress that this indicator should not be perceived as a proxy for political knowledge in general. We will, however, gain new insight into the relationship between media exposure and an additional type of knowledge related to domestic politics. Thus, our contribution to current comparative research is to extend the type of knowledge measurement used. ${ }^{1}$ Finally, we control for both individual and aggregate level variations in our study. By using a multilevel analysis technique, we show how both individual media use and country-specific media features may be related to knowledge about immigration.

\section{Media Use and Political Knowledge}

Several studies have demonstrated that the well-informed citizen is not only more likely to be attentive to politics and engaged in various forms of participation (Delli Carpini \& 
Keeter 1996, Ellis 2003, Strømsnes 2003), he/she is also more committed to democratic principles and has better-informed opinions (see Bizer et al. 2004 for a review). Thus, political knowledge not only aids in the construction of real interest, but it also helps assure that such interests will become part of the governing process.

In order to express attitudes and act in their own self-interest, citizens need relevant and up-to-date information about current affairs. This holds regardless of whether one considers the competence of individual citizens or the competence of the public as an aggregate. In many respects, politically relevant information is more widely available now than at any time in history, but what people learn from their media use is highly dependent on their media habits. Prior (2005) and Bennet (1998) have shown that those who prefer entertainment programmes learn less than those with a preference for news broadcasts. This finding also suggests that motivation may be important. Luskin (1990) goes as far as to say that motivation and intelligence are the only factors that promote political sophistication. Neither education nor media exposure as such make people more politically enlightened.

Most scholars would agree that watching news and current affairs rather than entertainment will have a greater impact on the audience's political knowledge, or as Patterson (2002) argues: "Watching some news, no matter how bad the content is, is better than watching no news at all." Within the scientific community, however, two divergent positions can be seen regarding whether news media (or media in general) may have a positive or negative influence on the public. According to the "media malaise argument", modern media - especially TV - tend to create political cynicism and apathy, withdrawal from the sphere of public life, social isolation and consequently loss of social capital (Robinson 1976, Patterson 1993, Postman 1985, Putnam 1995, Cappella \& Jamison 1997, Ansolabehere et al. 1994, 1995, 1999, Mutz \& Reeves 2005). Both the content and format of the modern media are seen as causes of this misery. The audience reacts by retreating from politics, by losing both their confidence and their interest. According to the more optimistic "cognitive mobilization argument", the modern media (together with a higher level of education) contribute to a significant increase in people's political skills, interest and engagement (Inglehart 1970, 1977, 1990, Dalton 1984, 1988, Norris 1996, 2000).

The ongoing debate between adherents to the "media malaise" and the "cognitive mobilization" camps touches upon a number of questions, and the actual arguments presented in the research literature are, of course, much more sophisticated and nuanced than this brief presentation suggests. In the present study, the focus is on the question of media use and people's knowledge about an issue that is at the top of political agendas in Western countries - immigration. More precisely, we are exploring if and how TV viewing influences political knowledge about immigration across different countries and media systems.

A vast majority of the "malaise vs. cognitive mobilization literature" is based on studies conducted on the American case. In the commercial US media system, news tends to be broadcasted at an early fringe time. Some studies have also demonstrated how the American media system gives relatively little attention to public and foreign affairs. During the past two decades, "soft news" has grown at the expense of "hard news" on American network television (Hamilton 2004: 184). According to one estimate, the time devoted to entertainment, disasters and accidents more than doubled in 
network television newscasts between 1990 and 1998 at the expense of public affairs coverage (Bennet 2003: 14). A central fear expressed by several European commentators has been that political information and discussion will be marginalized in a commercial system. Traditionally, media systems based on public broadcasting have broadcast news at the heart of prime time (Semetko 2000, Hallin \& Mancini 2004: 280). Although some scholars have identified trends of Americanization of European media systems, "information programmes" still account for a substantial proportion of both total and prime-time output in much of West-European television (Curran 2002: 192).

Blumler and Gurevitch (1995: 75) stress that political communication researchers have a tendency to implicitly presume that research findings from one society (normally one's own) are applicable everywhere. In this case, there are reasons to argue that important differences may exist in terms of the amount and quality of information provided to the public in different countries. This may influence the various publics' political knowledge (Aalberg 2006, Iyengar et al. 2009, Aalberg et al. 2008, Curran et al. 2009). Therefore, the benefits of a comparative research design are not only that we can test whether the hypotheses have more universal value, but also that we can check for systematic differences across countries.

If commercial, competitive and TV-dominated media systems provide poor news quality, will citizens in these environments be less knowledgeable and have greater misperceptions in relation to important political issues? Some studies already suggest such a pattern. Dimock and Popkin (1997) indicate that Europeans are much better informed about world events than Americans are, and they suggest that this is due to "substantial differences between countries in the communication of knowledge by TV" (1997: 223). However, the authors are not able to specify the nature of these differences, nor do they seek to explore whether there is a systematic relationship of the kind they suggest. Still, some attempts to pursue a comparative empirical analysis of the information environment and levels of political knowledge have been made by Milner (2002) and HoltzBacha and Norris (2001). Milner (2002: 102) demonstrated that there are systematic comparative differences in political knowledge based on a country's TV dependency score (the relationship between the percentage following commercial television and the percentage reading newspapers). Milner's study of 14 countries shows a strong negative correlation $(r=0.88)$ between the level of knowledge about the United Nations and the country's TV dependency score. In the US, which has the highest TV dependency score, the public knows very little about the UN. At the other end of the scale we find Norway, with the highest level of UN knowledge and the lowest TV dependency score.

On the individual level, Holtz-Bacha and Norris (2001) find a significant positive correlation between self-reported exposure to public television news programmes and levels of factual knowledge about the European Union. The authors conclude that their findings support pessimistic expectations concerning the consequences of the introduction of commercial broadcasting. In most countries, higher levels of knowledge are positively and significantly correlated with preferences for public broadcasting, and in particular with a preference for public TV combined with regular exposure to the news. They do suggest, though, that this is caused by an interactive process rather than by simple, unidirectional causation. As opposed to Milner (2002), Holtz-Bacha and Norris (2001) do not find a systematic pattern that underlies the ranking of the 16 West European countries included in their study (2001: 133). Therefore, they stress that future research 
on political knowledge and media use also needs to include more detailed information about the patterns of television broadcasting and the contents of programming. We argue that the type of knowledge being studied should also be considered.

Typically, political knowledge is defined as "the range of factual information about politics stored in long-term memory" (Delli Carpini \& Keeter 1996: 10). Hence, knowledge is discerned from issue positions, attitudes and values. Knowledge is neither a cognitive process nor merely any belief about or notion of reality: It is a realistic concept of reality. However, much of the factual knowledge people are questioned about is often irrelevant or trivial in relation to the use of knowledge that is of interest to researchers. Knowing the name of the president of the European Commission or the exact number of MPs is hardly instrumental when it comes to choosing which party to vote for. An important contribution to current research would therefore be to include knowledge questions that are more relevant to major political debates over controversial issues knowledge that may have a stronger impact on voters' policy preferences.

\section{The Issue of Immigration}

In the majority of Western countries, immigration has evolved into a major and controversial policy issue. In Western Europe, immigration from non-Western countries is increasingly seen as a problem, and a number of measures have been taken to reduce it. These measures include tighter legislation, increased patrolling of borders and even barbed-wire fences in enclaves of Ceuta and Melilla. Additionally, worrying signs of rising xenophobia and increasing support for extreme-right political parties have been observed in a number of West-European countries (Norris 2005, Pettigrew 1998). In the US, immigration is once again at the centre of "big" politics, and a heated debate has emerged that revolves primarily around the issue of illegal immigration. The US has also employed tight border controls and barbed-wire fences in an attempt to control or reduce immigration, while legislation reform is currently a highly contentious issue.

Quite clearly, relatively strong migrational pressures and increasing sizes of immigrant populations are among the most important reasons for the political prominence of the immigration issue. Public support for restrictive immigration policies and general attitudes towards immigration and immigrants are often based on public perceptions of immigrant sizes. These perceived sizes do not necessarily correspond to the actual sizes, and indeed, there is a fair amount of evidence that the public generally overestimates the sizes of immigrant and other minority populations. In the US, immigration is changing the racial composition of the country, and Whites are projected to become a numerical minority around the year 2050 (National Research Council, 1997). ${ }^{2}$ However, a study by Alba et al. (2005) shows that already by the year 2000 about one half of Americans thought that Whites had already become a numerical minority. The same study reports gross overestimates of several different minority groups in the US, often amounting to "fairly extreme distortions of national demography" (Alba et al. 2005: 911). Similar results showing strong overestimates of minority populations in the US have been presented by several additional studies (Gallagher 2003, Nadeau et al. 1993, Nadeau \& Niemi, 1995, Sigelman \& Niemi, 2001). In Europe, fewer relevant studies have been conducted, but the existing results generally show strongly inflated estimates of minority 
population sizes. Using the same ESS data as we do, Sides and Citrin (2007) find that the respondents overestimated the sizes of immigrant populations in all 20 European countries included in their study. The authors report that: "Respondents in every country overestimated the percentage of immigrants in their country, often by a substantial amount" (Sides \& Citrin, 2007: 487). A study of German respondents conducted by Semyonov et al. (2004) showed similar results: Germans perceived the size of the foreign population in their country to be almost twice its actual size.

These widespread size misperceptions have important consequences. Alba et al. (2005) find that their white American respondents who have distorted perceptions of the size of minority populations tend to have particularly negative attitudes towards immigrants, Blacks and Hispanics. In Europe, similar results have been obtained. Sides and Citrin (2007) find that European respondents who overestimate the number of immigrants are more opposed to both immigration and immigrants, and Semyonov et al. (2004) find that overestimates of immigrant population size lead to more negative attitudes towards immigrants in Germany. In several European countries, the negative attitudes towards immigrants that are (partly) a result of lack of knowledge about the number of immigrants also contribute to increased support for extreme, right-wing political parties. Norris (2005) finds that individuals with negative attitudes towards immigrants and immigration are more likely to vote for extreme, right-wing parties, and that this result holds even after controlling for a large number of additional variables (Norris 2005: 182-184).

Some of the authors blame the educational system for the problems associated with the observed low levels of knowledge. Thus Alba et al. (2005) conclude that their findings "...highlight the frequently overlooked value of an old bromide against prejudice: education." (Alba et al. 2005: 901). While this is certainly correct, it can also be argued that much of the information about immigration that individuals possess is acquired through the mass media. Therefore, more studies of media influence are needed, and in the present article we are trying to address this need.

\section{Hypotheses}

Based on our review of previous literature, we have arrived at five hypotheses as to what to expect from the empirical analysis. Three of the hypotheses are related to the aggregate level (H1, H2 and H5) and two are related to the individual level ( $\mathrm{H} 3$ and $\mathrm{H} 4)$.

H1. Countries with a high proportion of public service television will have higher levels of knowledge about immigration than countries with a low share of public service television.

H2. Countries with a democratic corporatist media system will have higher levels of knowledge than countries with a liberal or polarized pluralist media system. Knowledge about immigration will be lowest in liberal countries due to their low level of public service television.

H3. Citizens who watch a great deal of television news will have higher levels of knowledge about immigration than citizens who do not watch a great deal of news on television. 
H4. Citizens who watch a great deal of television in general will have a lower level of knowledge about immigration than citizens who do not watch a great deal of television in general.

H5. The relationship between citizens' exposure to television news and knowledge about immigration will be stronger in countries with higher shares of public service television.

\section{Data and Methods}

The main sources of data for our study are the 2002-2003 wave of the European Social Survey (ESS), and the US "Citizenship, Involvement and Democracy" (CID) survey that was conducted by the Center for Democracy and Civil Society (CDACS) at Georgetown University in 2005 (Howard et al. 2005). The CID survey replicates large parts of the ESS survey and the merged CID-ESS file provided by CDACS was used in the present analyses. ${ }^{3}$ In addition, we used OECD data on the sizes of immigrant populations in the countries included in the study. We focus on Western countries in our analyses, and our sample consists of 17 European countries and the US. The data are weighted in such a way that each country has an equal number of respondents. The equal size weight is combined with the design weight, which corrects for the inequalities in selection probability caused by the sampling design.

The American partial replication of the ESS we use does not contain measures of newspaper and radio consumption that are available for European countries. Thus, in the present study, we are restricted to only examining the relationship with TV consumption. We chose this type of study instead of a more thorough study of European countries for mainly two reasons. First, television is generally considered to be the most powerful medium. Second, truly comparative data sets containing both European countries and the US are much rarer than data sets including European countries only (e.g., Eurobarometer, ESS in its original form, etc.). For this reason, there is perhaps a greater need for studies including both Europe and the US.

For practical reasons, we do not include media content data in our analysis. Although some previous studies on the relationship between media and political knowledge have included assessment of differences in media content, these have typically been limited to single-country studies. Important exceptions are studies on EU knowledge that have relied on content data from Monitoring Euromedia. This is a study of media coverage in the European Union primarily about EU issues in newspapers, but television media content is also included for six of the member states. Although this source provides the most comprehensive cross-national content analysis data set currently available, it is not suitable for our project. As the aim of our study is to compare media system difference and difference in knowledge about immigration, we would argue that detailed media content data are not vital for our analysis.

\section{Individual-level Variables}

The dependent variable in our analyses is a continuous measure of how inaccurate a respondent's knowledge of the size of the immigrant population in his/her country is. 
The variable, called Size misperception, is calculated as the absolute value of the difference between the real size of the country's immigrant population and the individual's perception of this population's size. More precisely, the value of the Size misperception variable for an individual $i$ from a country $j$ is calculated as follows:

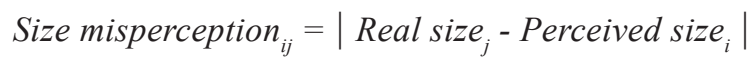

The size misperceptions are expressed in percentage points. For example, the value 10 means that the individual has evaluated the size of the immigrant population in her/his country to be 10 percentage points larger or smaller than it actually is. The measure of real sizes of immigrant populations (country-level variable Real size) was constructed on the basis of data from OECD (2005) and OECD (2007) and measures the percentage of the country's population that is made up of foreign-born individuals. ${ }^{4}$ The measure of a respondent's perception of the size of immigrant population in his/her country (individual-level variable Perceived size) is constructed on the basis of this question from the survey: "Out of every 100 people living in [country], how many do you think were born outside [country]?". Thus, the values of the measure express respondents' estimates of the percentage of foreign-born in their country. ${ }^{5}$

Respondents' TV viewing is captured by two variables. The first variable, $T V$ total, measures the total time respondents spend watching television daily. The variable is measured on a five-point scale (1 - "No time at all" to 5 - "More than 3 hours") and is based on the following question from the survey: "On an average weekday, how much time, in total, do you spend watching television?" The second variable, TV news, measures the time respondents spend watching news or programmes about politics and current affairs. The variable is measured on an eight-point scale (1 - "No time at all" to 8 - "More than 3 hours"), and is based on the following question from the survey: "... on an average weekday, how much of your time watching television is spent watching news or programmes about politics and current affairs?"

A number of control variables are also included in the models. The variable Female is a dummy variable coded "1" for females. The variable Education measures the respondent's level of education on a 7-point scale, while Age measures the age of the respondent (in years). ${ }^{6}$ In addition to these "classical" sociodemographic control variables, we also include variables known to specifically influence estimates of size of the minority population. As Alba et al. (2005) point out, it is reasonable to expect the size estimates to vary according to the degree of everyday exposure to minorities and immigrants, such that individuals who have more exposure to immigrants report higher estimates of the number of immigrants. For this reason, we also include controls for size of the place of residence (knowing that immigrants tend to be more concentrated in big cities) and nativity (as immigrants tend to have more contact with other immigrants). The size of place of residence is operationalized as the variable Urbanity, with values of the variable varying from 1 - "a farm or home in the countryside" to 5 - "a big city". Nativity is operationalized as the dummy variable Immigrant, coded "1" for foreign-born respondents.

\section{Country-level Variables}

We implement the tripartite media systems classification of Hallin and Mancini (2004: 67) by creating dummy variables for the North Atlantic or Liberal and the Mediterranean 
or Polarized Pluralist models, and using the North/Central European or Democratic Corporatist model as a reference category. The following countries are classified as belonging to the Liberal model: the UK, Ireland and the US. Spain, France, Greece, Italy and Portugal are classified as belonging to Polarized Pluralist model. Finally, Austria, Belgium, Switzerland, Germany, Denmark, Finland, Netherlands, Luxembourg, Norway and Sweden are classified as belonging to the reference category - Democratic Corporatist model.

The variable Public TV share measures the share of public service television in the countries in our study. The variable is coded based on data from Djankov et al. (2003) and measures the share of public ownership of the five largest TV stations in a given country as of December 1999. To check for consistency of the data in relation to other ways of measuring the share of public service TV, we compared our data with the data from Norris (2000: 95-96), which measure the audience share of public TV channels in 1997. The two measures are very similar, and the correlation between them is 0.82 .

We also code a country-level variable measuring the percentage of respondents in a country that have "correct" or "accurate" perceptions of the size of the immigrant population in their country. We define an individual's size perception to be correct if it is less than five per cent larger or smaller than the real value of the immigrant population size in her/his country. The variable is named Percentage correct perceptions.

\section{Results}

The real sizes of foreign-born populations, as well as the average values of the perceived sizes and the size misperceptions in the countries in our analyses are presented in Table 1. The countries in the table are ordered by values of the misperceptions. These vary from about 5 percentage points in Finland to about 18-19 percentage points in the US and France. The general impression is that citizens of Nordic countries tend to have quite accurate perceptions of immigrant size, while the French, Americans and Britons have particularly incorrect perceptions. To a certain degree, this is influenced by our operationalization of misperceptions as values of perceived size that are either lower or higher than the real size. Obviously, in countries like Finland or Denmark, which have few immigrants, it is difficult to underestimate the immigrant population size. Thus, the misperceptions are almost exclusively overestimates. However, if we focus only on overestimates (an approach that favours countries with large immigrant populations), we get very similar results. The largest overestimates are made in France, the UK and the US, while the smallest are from Denmark, Finland, Ireland and Norway. ${ }^{8}$

If we look at the Percentage with correct perceptions measure in Table 1, a similar pattern emerges. The proportion of the population with accurate perceptions of immigrant population size vary from about 74 per cent in Finland to about 21 per cent in the US. Note that the differences between the countries are very large: While almost three quarters of Finns are knowledgeable about immigrant population size, this can be said of only one in five Americans. The reasons for these differences in knowledge about immigrant population size are probably complex, and may include differences in educational composition, prominence of immigration issues in the public debate and so forth. However, we are primarily interested in the influence of media systems, and we may speculate on whether the differing shares of public TV in the countries in our sam- 
Table 1. Real and Perceived Sizes of Foreign-born Populations, the Size of the Misperceptions and Percentage with Correct Perceptions (percentage points)

\begin{tabular}{lrccc} 
& Real size & Perceived size & Misperceptions & $\begin{array}{c}\text { Percentage with } \\
\text { correct perceptions }\end{array}$ \\
\hline Finland & 2.54 & 6.73 & 5.16 & 73.98 \\
Denmark & 6.73 & 10.14 & 6.46 & 68.53 \\
Norway & 7.33 & 12.18 & 8.43 & 52.55 \\
Ireland & 10.38 & 14.6 & 9.82 & 33.01 \\
Germany & 11.12 & 19.88 & 11.5 & 37.66 \\
Austria & 12.48 & 20.26 & 11.57 & 35.35 \\
Spain & 5.32 & 16.23 & 11.65 & 50.05 \\
Greece & 10.27 & 20.12 & 11.88 & 36.06 \\
Sweden & 12.01 & 20.29 & 12.19 & 33.6 \\
Switzerland & 21.55 & 28.06 & 12.59 & 31.46 \\
Italia & 3.93 & 17.57 & 14.31 & 33.6 \\
Belgium & 10.68 & 23.11 & 15.02 & 32.4 \\
Netherlands & 10.1 & 23.53 & 15.27 & 30.22 \\
Luxemburg & 32.45 & 40.58 & 15.35 & 22.2 \\
Portugal & 6.29 & 20.78 & 15.42 & 42.34 \\
United Kingdom & 8.28 & 23.86 & 17.69 & 28.16 \\
USA & 12.8 & 28.22 & 18.38 & 21.4 \\
France & 10.03 & 27.78 & 19.1 & 25.12 \\
\hline
\end{tabular}

Note: The Perceived size is a country's average value of respondents' perceptions of the size of the immigrant population. The Misperceptions measure is calculated as a country's average value of: abs (Perceived size - Real size). Percentage with correct perceptions shows the proportion of respondents whose size perceptions diverge less than $+\backslash-5 \%$ from the real size.

ple can explain some of the observed knowledge differences. For a simple check of this possibility, we use a scatter plot with a regression line that is presented in Figure 1.

At first glance, there seems to be some influence of the share of public TV on knowledge. The slope of the regression line is in the expected direction: a larger share of public service TV tends to be associated with a higher degree of knowledge. However, we can also see that the value of the regression coefficient is not significantly different from zero ( $p$-value $=0.23$ ), that only about ten per cent of the variance in knowledge is explained, and that the positive slope of the regression line is heavily influenced by the outlying values for Finland and Denmark. Thus, our conclusion here is that we do not find any clear association between the share of public TV and knowledge. As we shall see, a more sophisticated analysis presented later on produces the same result.

Let us now proceed with the more sophisticated, multilevel analyses of individuallevel and country-level determinants of knowledge. In all further analyses, we will use Misperceptions as the dependent variable.

We begin by estimating the intercept-only model, defined by:

$$
Y_{i j}=\beta_{0 j}+u_{0 j}+e_{i j}
$$

where the dependent variable is Misperceptions, beta is the intercept, $e$ is level-1 residual and $u$ is level- 2 residual. The subscript $i$ varies across the level-1 units (respondents) 
Figure 1. Share of Public Service TV and Percentage Correct Answer. Scatterplot with the regression line

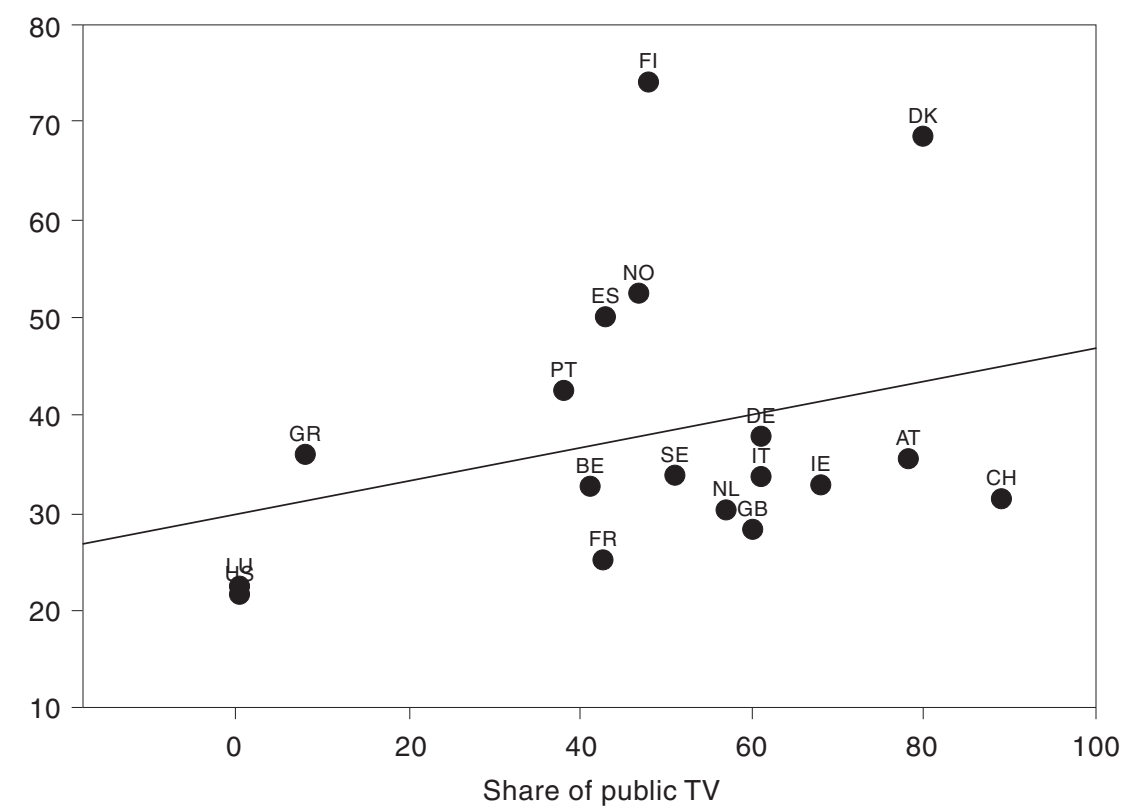

Note: Correct perceptions are defined as perceptions that diverge less than $+/-5 \%$ from the actual size of the immigrant population in the country.

$\mathrm{R}^{2}=0.09 ; \mathrm{p}$-value for the regr. coeff. $=0.227$

and subscript $j$ varies across level-2 units (countries). After estimation of the model we calculate the Variance Partition Coefficient ${ }^{9}$ (VPC) using equation (3):

$$
\operatorname{VPC}=\frac{\operatorname{Var}\left(u_{0}\right)}{\operatorname{Var}(e)+\operatorname{Var}\left(u_{0}\right)}
$$

where $\operatorname{Var}(e)$ is the variance of level-1 residuals (variance at the individual-level), and $\operatorname{Var}\left(u_{0}\right)$ is the variance of the level-2 residuals (variance at the country-level). In our model, the variance of the level-1 residuals equals 193.81, while corresponding value for level-2 residuals is 14.06 . The VPC thus equals 0.138 . This means that around 6.8 per cent of the total variance in knowledge about immigrants can be attributed to differences between level-2 units (countries). Both the t-test and the likelihood ratio test show that the coefficient for the variance of the level-2 residual is highly significant, and we therefore conclude that multilevel analysis is necessary. ${ }^{10}$

We now include our independent variables into the multilevel models presented in Table 2. We build the models gradually. First, only the two measures of TV viewing are included (Model 1), thereafter all level-1 controls and Share of public TV variable are added (Model 2). Finally, the cross-level interaction between Share of public TV and TV News is included into Model 3 in order to test Hypothesis 5.

Before interpreting the results, we should recollect that our dependant variable measures lack of knowledge. Therefore, the negative effects of an independent variable indicate an increase in knowledge with increasing values of the independent variable, and vice versa. As one can see, the effects of the measures of TV viewing in Model 1 
Table 2. Regression of the Misperceptions of the Percentage of Foreign-born on Individual- and Country-level Regressors (Two-level model estimated by SPSS)

\begin{tabular}{lcccccc} 
& \multicolumn{2}{c}{ Model 1 } & \multicolumn{2}{c}{ Model 2 } & \multicolumn{2}{c}{ Model 3 } \\
& $\mathrm{b}$ & s.e. & $\mathrm{b}$ & s.e. & $\mathrm{b}$ & s.e. \\
\hline Intercept & $9.69^{* * *}$ & 0.90 & $15.544^{* * *}$ & 1.787 & $15.748^{* * *}$ & 1.745 \\
Level-1 variables & & & & & & \\
$\quad$ TV total & $1.43^{* * *}$ & 0.09 & $0.800^{* * *}$ & 0.091 & $0.798^{* * *}$ & 0.091 \\
TV news & $-0.58^{* * *}$ & 0.07 & -0.138 & 0.071 & -0.200 & 0.134 \\
Female & & & $3.498^{* * *}$ & 0.162 & $3.495^{* * *}$ & 0.162 \\
Education & & & $-1.569^{* * *}$ & 0.059 & $-1.570^{* * *}$ & 0.059 \\
Age & & & $-0.055^{* * *}$ & 0.005 & $-0.055^{* * *}$ & 0.005 \\
Urbanity & & & $0.607^{* * *}$ & 0.071 & $0.605^{* * *}$ & 0.071 \\
Immigrant & & & $2.613^{* * *}$ & 0.289 & $2.608^{* * *}$ & 0.289 \\
Level-2 variables & & & & & & \\
Share of public TV & & & -0.037 & 0.032 & -0.041 & 0.031 \\
Sh. of public TV*TVnews & & & & & 0.002 & 0.003 \\
Deviance (-2LL) & $\mathbf{2 2 9 3 7 3 . 9 1}$ & $\mathbf{2 2 4 0 0 9 . 0 2}$ & $\mathbf{2 2 4 0 0 7 . 4 9}$ \\
\hline
\end{tabular}

Note: *Significant at 0.05 level; **Significant at 0.01 level; ***Significant at 0.001 level. Only fixed parts of the models are presented.

are in accordance with the findings of previous studies. TV viewing in general has a negative influence on knowledge, while watching news and programmes about politics and current affairs increases knowledge. However, if we control for other relevant predictors of knowledge as we did in Model 2, we see that the relationship between exposure to TV news and knowledge about immigration is no longer significant. ${ }^{11}$ Thus, our results clearly support Hypothesis 4 (TV viewing in general is associated with lower knowledge), but we do not find strong support for Hypothesis 3. Although the relationship is in the expected direction, the weak and non-significant coefficient indicates that citizens who watch a large amount of TV news do not necessarily learn much more about immigration.

Regarding the influence of the share of public TV on knowledge, we can see that the sign of the coefficient in Model 2 is negative, as expected. However, the coefficient is not significantly different from zero at the 0.05 level of significance. Our conclusion is that we did not find strong enough support for Hypothesis 1. Therefore, we cannot say that countries with a high proportion of public service television generally have higher levels of knowledge about immigration. It is important to emphasize that our results concern one particular measure of knowledge in 18 countries. They do not prove that other indicators of political knowledge will also be unrelated to the share of publicly owned TV channels.

In Model 3, we have included the cross-level interaction between Share of public TV and $T V$ news variables in order to conduct an appropriate statistical test of Hypothesis 5, which predicts a stronger covariance with news watching in countries with a large share of public service TV. As we can see, the coefficient of the interaction term is very close to zero, and clearly not statistically significant. The chi-square test also fails to show any significant improvement in the model after introduction of the interaction term. ${ }^{12} \mathrm{We}$ also ran Models 2 and 3 with the measure of share of public TV based on the audience share 
Figure 2. Effects of News Watching on Misperceptions (absolute). Controlled all level-1 predictors Included in Table 2.

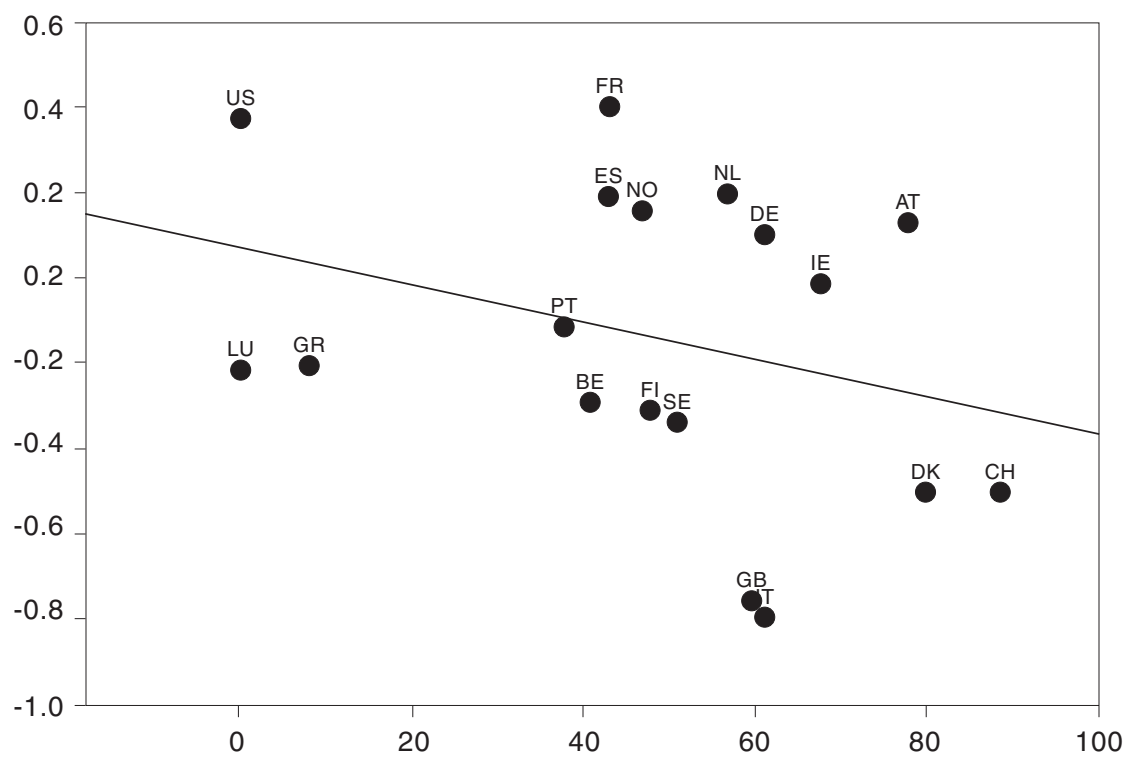

Note: Value or regr. coeff. $=-.004 ; \mathrm{p}$-value $=.210 ; \mathrm{R}$ square $=.096$

data from Norris (2000). The results remained basically the same, with a negative nonsignificant coefficient of "public TV share" in Model 2, and a positive non-significant interaction term in Model 3. A more detailed, although somewhat simplified, view of the differences in effects of news watching can be obtained from Figure 2.

Again, our first impression from looking at Figure 2 is that a larger share of public TV in a country leads to a more positive relationship between news-watching and knowledge due to the negative slope of the regression line. However, the value of the regression coefficient is very low and not statistically significant. Based on these results and the results from Model 3, we can clearly conclude that the relationship between news watching and knowledge about immigration is not generally stronger in countries with higher shares of public TV ownership. Thus, Hypothesis 5 has to be rejected.

Hypothesis 2 states that we expect citizens of countries with a democratic corporatist system to have higher levels of knowledge than citizens of countries with a liberal or polarized pluralist media system. In order to test this hypothesis, we replace the Share of public $T V$ variable in Model 2 with two dummy variables, one representing countries with a liberal media system, and another representing countries with the polarized pluralist system. The effects of level-1 predictors are roughly the same as in Model 2, and we will not present them once again. Regarding the two level-2 dummies, the coefficient of North Atlantic or Liberal system measures equals 3.27 (p-value $=0.14$ ), while the coefficient for Mediterranean or Polarized Pluralist system measures equals 1.75 $(\mathrm{p}$-value $=0.35)$. As we can see, the model predicts higher misperceptions in countries with liberal and polarized pluralist media systems as compared with countries with a democratic corporatist system (reference category). However, none of the coefficients is statistically significant and our conclusion is that we have to reject Hypothesis 2. 


\section{Discussion}

The purpose of the present study has been to investigate if and how TV viewing may influence public knowledge about the issue of immigration in 18 countries. We have also asked whether the level of knowledge and media effects vary systematically according to the countries' media systems.

While simple analyses seem to support many of our hypotheses, more stringent tests reveal that there is no clear relationship between the level of knowledge about immigration and our aggregate measures of media structure. Using a multilevel analysis technique, we found no evidence of a strong relationship between a country's share of public service television and public knowledge on immigration. Similarly, the covariance between knowledge about immigration and exposure to news and current affairs was not significantly higher in countries with a high share of public TV.

At first glance, the analysis also suggests that citizens living in countries classified as having a democratic corporatist media system tended to be more knowledgeable than those exposed to either a liberal media system or a polarized pluralist system. But after more thorough tests, the coefficients are no longer significant. As we have seen, there are large differences between the countries regarding levels of knowledge about immigration; the percentage of respondents with roughly correct perceptions varies from about 70 per cent in Finland and Denmark to only slightly more that 20 per cent in the US, Luxemburg and France. However, these differences do not seem to have much to do with the countries' media systems, as defined by Hallin and Manchini (2004), or with the share of public TV in the country. Data from the European Election Studies do indicate that there is some between-country variation in how important immigration issues are considered to be. If media coverage of these issues is more intense in countries where the public considers them to be more salient, this could result in knowledge differences that are not related to media systems. ${ }^{13}$

At the level of the individual, the positive relationship between exposure to news and current affairs and knowledge about immigration is no longer significant after controlling for other relevant factors. The negative covariance between watching TV in general, however, remained relatively strong and highly significant. How can we interpret this?

The fact that the negative relationship between knowledge about immigration and time spent watching television in general remained strong even after more stringent tests can be interpreted in two ways, depending on the assumed direction of causality. This could be the result of a negative media effect that causes large-scale consumers of TV in general to overestimate the number of immigrants in the country. Alternatively, causality may be working in the reverse direction. We cannot rule out the possibility that the politically ignorant choose to spend more of their time watching television in general.

From a normative point of view, however, we should perhaps be more concerned about the very weak and non-significant effect of news and current affairs exposure on knowledge about immigration. After all, the main purpose of news and current affairs is to keep citizens informed about what is going on in society and politics. Others have previously demonstrated such a positive effect (e.g., Newton 1999, Norris 2000, Milner 2002), but could this have been based on their limited sample, their simple analyses or the knowledge questions used? Different approaches may produce different results.

We believe at least two additional explanations may clarify why we found no clear relationship between exposure to news and current affairs and knowledge about immi- 
gration. One is related to Luskin's (1990) argument that motivation and intelligence are the only factors that promote political sophistication. If people are not interested in the issue, neither education nor media exposure as such will make them more knowledgeable. In our analysis, the effect of TV news exposure was significantly reduced after controlling for variables that can typically be related to a special interest in the issue of immigration.

Another explanation is related to the actual content of the news to which respondents had been exposed. For practical reasons, our analysis did not include data on news content. Perhaps the issue of immigration and the share of immigrant populations were rarely discussed in the news reports prior to the completion of the opinion surveys. The relationship between news media exposure and knowledge about immigration may also be influenced by the way the media frame this issue. Some studies have suggested that news coverage on immigration is particularly biased. Roggeband and Vliegenthart (2007) found that the Dutch news media presented a much more hegemonic framing of immigration issues compared to the diversity of framings used in the parliamentary debates. Moreover, another study reveals that increasing the number of news reports about immigration-related topics typically led to higher support for anti-immigrant parties (Boomparden \& Vliegenthart 2007). Future research should therefore take a closer look at the quantity and quality of information provided by the news media on a number of issues as well as at the relationship between exposure to these news media and citizens' political knowledge.

\section{Notes}

1. Future comparative studies should seek to include a larger variety of political knowledge items, including both different foreign and domestic policy dimensions.

2. The accuracy of such long-term projections is highly questionable, but they provide a vivid illustration of the changes in ethnic composition.

3. The data were downloaded from: http://www8.georgetown.edu/centers/cdacs//cid/data.htm .

4. The values of the Real size variable are presented in Table 1.

5. The respondents are asked to estimate the size of the population of so-called "first generation" immigrants. In some countries, the most commonly reported definitions of immigrant populations also include individuals with one or two immigrant parents (so-called "second generation"). This may lead to the lower accuracy of the estimates of individuals who live in countries in which the second generation is included in the definitions. However, the differences that arise in this case seem to be relatively modest. For instance, the most common definition of immigrant population in Norway includes individuals born in the country that have two foreign-born parents. According to this definition, $9.7 \%$ of the population are immigrants at the time of writing. If one uses only the first generation, the immigrant population is only slightly smaller, numbering $8 \%$ of the total (Statistics Norway, 2009). Even in countries like Belgium, which have an "older" immigrant population and therefore a larger second generation, the different ways of including the second generation result in about four percentage points difference in estimates of immigrant population (Council of Europe 2003).

6. There were minor differences in measurement of educational level in the US (8 point scale) and the European countries ( 7 point scale). We have rescaled the American variable to the 7 point scale by collapsing values 3 ("High school grade") and 4 ("GED") into a single category.

7. Respondent income is also usually included as a control variable (e.g., Holtz-Bacha \& Norris, 2001). However, there is a large proportion of missing values on income for some of the countries, with a maximum percentage of 42 per cent in Spain. For this reason, we do not include income in the final models. Preliminary tests in the countries with low missing values on income show that the results of the analyses remain essentially the same after additionally controlling for income.

8. The overestimates are simply the difference between the real and the perceived sizes in any given country (the first two columns in Table 1). Note that the average values of the perceived sizes are larger than the real sizes in all of the countries. Thus, the respondents tend to perceive foreign-born populations to be 
bigger than they really are in all of the countries. More details about the differences between real and perceived sizes of immigrant populations in the countries included in the ESS can be found in Sides and Citrin (2007) and Strabac (2007). The analysis of Strabac (2007) shows that these differences are statistically significant in all of the Western European countries.

9. In a two-level model, the VPC is identical to the more commonly used term Intra-Class Correlation (ICC). However, as Goldstein (2003: 17) points out, use of the term ICC in the discussion of the variance partition may be confusing, and the clearly defined term VPC is more appropriate.

10. In models with a low number of level-2 units such as ours, testing the significance of variance components by using estimated standard errors and $\mathrm{z}$ - or t-tests is somewhat problematic, because the sampling distribution of the variance estimates is skewed to an unknown degree (Raudenbush \& Bryk 2002: 55). Rasbash et al. (2003) recommend use of the likelihood ratio test as a preferred test. We will thus perform the latter test when discussing both the goodness of fit of the models and the significance of the variance components.

11. The TV news coefficient is actually close to the conventional 0.05 level of significance (p-value $=0.051$ ), but in a large sample such as ours this is far from impressive.

12. The difference in the degrees of freedom between Models 2 and 3 actually equals three. This is because two additional coefficients in the random part of the models (not shown in Table 2) are estimated in Model 3.

13. Assuming roughly equal quality of the news coverage.

\section{References}

Aalberg, T. (2006) 'Media Systems, News Content and Public perception of Political Reality', Research proposal submitted to the Norwegian Research Council's 'Yngre fremragende forskere' program. Trondheim: NTNU.

Aalberg, T., P. van Aelst and J. Curran (2008) 'Media Systems and the Information Environment. An Empirical Study of Two Liberal and Four Democratic Corporatist Countries', Paper presented at the 26th Congress of the International Association for Media and Communication Research (IAMCR) Stockholm, Sweden July 20-25.

Alba, R., R.G. Rumbaut, and K. Marotz. (2005) 'A Distorted Nation: Perceptions of Racial/Ethnic Group Sizes and Attitudes Toward Immigrants and Other Minorities', Social Forces 84: 901-919.

Ansolabehere, S., S. Iyengar, A. Simon and N. Valentino (1994) 'Does Attack Advertising Demobilize the Electorate?', American Political Science Review 88: 829-838.

Ansolabehere, S. \& and S. Iyengar (1995) Going Negative. How Political Advertisements Shrink and Polarize the Electorate. New York: The Free Press.

Ansolabehere S., S. Iyengar and A. Simon (1999) 'Replicating Experiments using Aggregate and Survey Data: The case of Negative Advertising and Turnout', American Political Science Review 93: 901-909.

Bennet, S.E. (1998) 'Young Americans' Indifference to Media Coverage of Public Affairs', PS: Political Science and Politics 31: 535-541.

Bennet, W. (2003) News: The Politics of Illusion $5^{\text {th }}$ edition. New York: Longman.

Bizer, G.Y., P.S. Visser, M.K. Berent and J.A. Krosnick (2004) 'Importance, Knowledge, and Accessibility: Exploring the Dimensionality of Strength-related Attitude Properties', in Saris, W.E. \& P. Sneiderman (eds.) Studies in Public Opinion. Attitudes, Nonattitudes, Measurement Error, and Change. Princeton: Princeton University Press.

Blumler, J.G., and M. Gurevitch, (1995). The Crisis of Public Communication. London: Routledge.

Boomparden, H.G. and R. Vliegenthart (2007) 'Explaining the Rise of Anti-immigrant Parties: The Role of News Media Content', Electoral Studies 26: 404-417.

Cappella, J.N. and K.H. Jamieson (1997) Spiral of Cynicism. The Press and the Public Good. Oxford: Oxford University Press.

Curran, J. (2002) Media and Power. London: Routledge

Curran, J., S. Iyengar, A.B. Lund and I. Salovaara-Moring (2009) 'Media System, Public Knowledge and Democracy: A Comparative Study’, European Journal of Communication 24: 5-26.

Dalrymple, K.E. and D.A. Scheufele (2007) 'Finally Informing the Electorate? How the Internet got People Thinking about Presidential Politics in 2004', Harvard International Journal of Press-Politics 12: 96111.

Dalton, R.J. (1984) 'Cognitive Mobilization and Partisan Dealignment in Advanced Industrial Democracies', Journal of Politics 46: 264-284.

Dalton, R.J. (1988) Citizen Politics in Western Democracies: Public Opinion and Political Parties in the United States, Great Britain, West Germany, and France. New Jersey: Chatham House Publishers 
Delli Carpini, M.X. and S. Keeter (1996) What Americans Know about Politics and Why it Matters. New Haven, Conn.: Yale University Press.

de Vreese, C.H. and H. Boomgaarden (2005) 'News, Political Knowledge and Participation: The Differential Effects of News Media Exposure on Political Knowledge and Participation', Acta Politica 41: 317-341.

Dimock, M. and S. Popkin (1997) 'Political Knowledge in Comparative Perspective', in S. Iyengar and R. Reeves (eds.) Do the Media Govern? Beverly Hills: Sage.

Djankov, S., C. McLiesh, T. Nenova, and A. Shleifer (2003) 'Who Owns the Media?', Journal of Law \& Economics 46: 341-381.

Ellis, I.O. (2003) 'Politisk kunnskap blant norske velgere' [Political knowledge among Norwegian voters], in Aardal, B. (ed.) Velgere $i$ villrede. En analyse av stortingsvalget 2001 [Perplexed voters. An analysis of the 2001 Storting election] Oslo: Dam.

Fallows, J. (1996) Breaking the News. How the Media Undermine American Democracy. New York: Pantheon.

Gallagher, C.A. (2003) 'Miscounting Race: Explaining Whites' Misperceptions of Racial Group Size', Sociological Perspectives 46: 381-396.

Goldstein, H. (2003) Multilevel Statistical Models. London: Arnold.

Hallin, D.C. and P. Mancini (2004) Comparing Media Systems. Three Models of Media and Politics. Cambridge: Cambridge University Press.

Hamilton, J. (2004) All the News that's fit to Sell. Princeton: Princeton University Press.

Holtz-Bacha, C. and P. Norris (2001) “"To Entertain, Inform, and Educate”: Still the Role of Public Television', Political Communication 18: 123-140.

Howard, M.M., J.L. Gibson, and D. Stolle (2005) The U.S. Citizenship, Involvement, Democracy Survey. Georgetown University: Center for Democracy and Civil Society (CDACS)

Inglehart, R. (1970) 'Cognitive Mobilization and European Identity', Comparative Politics, 3: 45-70.

Inglehart, R. (1977) The Silent Revolution. Changing Values and Political Styles among the Western Publics. Princeton: Princeton University Press.

Inglehart, R. (1990) Culture Shift in Advanced Industrial Society. Princeton: Princeton University Press.

Iyengar, S., K.S. Hahn, H. Bonfidelli and M. Marr (2009) 'Dark Areas of Ignorance' Revisited: Comparing International Affairs Knowledge in Switzerland and California', Communication Research 36: 341-58.

Luskin, R.C. (1990) 'Explaining Political Sophistication', Political Behavior 12: 331-361

Milner, H. (2002) Civic Literacy. How Informed Citizens make Democracy Work. Hanover, NH: University Press of New England.

Mutz, D.C. and B. Reeves (2005) 'The New Videomalaise: Effects of Televised Incivility on Political Trust', American Political Science Review 99: 1-15.

Nadeau, R., R.G. Niemi, and J. Levine (1993) 'Innumeracy about Minority Populations', Public Opinion Quarterly 57: 332-347.

Nadeau, R. and R.G. Niemi. (1995) 'Educated Guesses - the Process of Answering Factual Knowledge Questions in Surveys', Public Opinion Quarterly 59: 323-346.

National Research Council (1997) The New Americans: Economic, Demographic, and Fiscal Effects of Immigration. Washington, D.C.: National Academy Press.

Newton, K. (1999) 'Politics and the News Media: Mobilization or Media Malaise?', British Journal of Political Science 29: 577-599.

Norris, P. (1996) 'Does Television Erode Social Capital? A Reply to Putnam', PS: Political Science \& Politics 29: 474-480.

Norris, P. (2000) A Virtuous Circle. Political Communications in Postindustrial Societies. Cambridge: Cambridge University Press.

Norris, P. (2005) Radical Right. Voters and Parties in the Electoral Market. Cambridge: Cambridge University Press.

OECD (2005) 'Database on Immigrants and Expatriates', Retrieved 2006/12/15/, (http://www.oecd.org/ dataoecd/18/23/34792376.xls ).

OECD (2007) OECD Factbook 2007, Retrieved 15.11. 2007, (http://puck.sourceoecd.org/pdf//fact2007pdf//12-02-01.pdf).

Patterson, T.E. (1993) Out of Order. New York: Vintage.

Patterson. T.E. (2002) The Vanishing Voter: Public Involvement in an Age of Uncertainty. New York: Knopf.

Pettigrew, T.F. (1998) 'Reactions toward the New Minorities of Western Europe', Annual Review of Sociology 24: 77-103.

Postman, N. (1985) Amusing Ourselves to Death. New York: Viking.

Prior, M. (2005) 'New vs. Entertainment: How Increasing Media Choice widens Gaps in Political Knowledge and Turnout', American Journal of Political Science 49: 577-592. 
Putnam, R. (1995) 'Tuning In, Tuning Out: The Strange Disappearance of Social Capital in America', PS: Political Science \& Politics 27: 664-683.

Rasbash, J., F. Steele and W. Browne (2003) A User's Guide to MLwiN Version 2.0. Documentation version 2.1e. London: Institute of Education, University of London.

Raudenbush, S.W. and A.S. Bryk (2002) Hierarchical Linear Models. Applications and Data Analysis Methods. Thousand Oaks, CA: Sage.

Robinson, M.J. (1976) 'Public Affairs Television and the Growth of Political Malaise: The Case of 'The Selling of Pentagon”, American Political Science Review 70: 409-432.

Roggeband, C. and R. Vliegenthart (2007) 'Divergent Framing: The Public Debate on Migration in the Dutch Parliament and Media, 1995-2004', West European Politics 30: 524-548

Schudson, M. (1995) The Power of News. Cambridge, MA: Harvard University Press.

Semetko, H.A. (2000) 'Great Britain: The End of News at Ten and the Changing News Environment', in Gunther, R. \& A. Mughan (eds.) Democracy and the Media. A Comparative Perspective. New York: Cambridge University Press.

Semyonov, M., R. Raijman, A.Y. Tov and P. Schmidt (2004) 'Population Size, Perceived Threat, and Exclusion: A Multiple-indicators Analysis of Attitudes toward Foreigners in Germany’, Social Science Research 33: 681-701.

Sides, J.M. and J. Citrin (2007) 'European Opinion about Immigration: The Role of Identities, Interests, and Information', British Journal of Political Science 37: 477-504.

Sigelman, L. and R.G. Niemi (2001) 'Innumeracy about Minority Populations - African Americans and Whites Compared', Public Opinion Quarterly 65: 86-94.

Statistics Norway (2009) 'Temaside for innvandring', [Topic page about immigration] Retrieved 28.1.2009, http://www.ssb.no/innvandring/

Strabac, Zan (2007) Ethnic Attitudes in Contemporary European Societies, PhD Thesis, Trondheim: Norwegian University of Science and Technology: Department of Sociology and Political Science.

Strømsnes, K. (2003) Folkets makt. Medborgerskap, demokrati, deltakelse. [The peoples power. Citizenship, democracy and participation.] Oslo: Gyldendal.

The Council of Europe (2003) The Demographic Characteristics of Immigrant Populations. Strasbourg: The Council of Europe Publishing.

TORIL AALBERG, Dr.polit., Associate Professor, Department of Sociology and Political Science, Norwegian University of Science and Technology / NTNU, Trondheim, toril. aalberg@svt.ntnu.no,

ZAN STRABAC, Ph.D., Post-doctoral Fellow, Department of Sociology and Political Science, Norwegian University of Science and Technology / NTNU, Trondheim, zan. strabac@svt.ntnu.no 